\title{
Computational model of Savonius turbine
}

\author{
Modelado computacional de turbina Savonius \\ Argemiro Palencia Díaz ${ }^{1} \quad$ Giovanni Jiménez Pajaro ${ }^{1} \quad$ Khriscia Utria Salas $^{1}$ \\ Recibido 29 de abril de 2014, aceptado 10 de noviembre de 2014 \\ Received: April 29, $2014 \quad$ Accepted: November 10, 2014
}

\begin{abstract}
Although vertical axis turbines have long existed, it was not until the beginning of the twentieth century when the Darrieus (1921) and Savonius rotors (1924) appeared; the two most used models nowadays. Savonius rotor was invented by the Finnish engineer Sigurd J Savonius with two half cylinders basic design that rotate around an axis. In this research, four different models of Savonius rotor blades are analyzed, as well as the traditional rotor. The principal aim of this research is to find the best Power Coefficient $(\mathrm{Cp})$ and the best torque coefficient $(\mathrm{Cm})$ for different models. In order to achieve the objective, a CFD computational model was used, with 3D simulations in transient regime. A computational domain was defined as a function of the minimal longitude in the system, and meshing is performed after a mesh size independency analysis. The results show that helical Savonius rotor performs the best in the analyzed operation conditions and improves in $\sim 20 \%$ above the other configurations. In addition, 3-blade rotor presents the lowest performance of all the models with a power coefficient $\mathrm{Cp}$ of 0.073 .
\end{abstract}

Keywords: Savonius, eolic energy, vertical turbine, numerical study, CFD.

\section{RESUMEN}

Las turbinas de eje vertical existen desde hace mucho tiempo, sin embargo, fue hasta principios del siglo XX cuando aparecieron dos de los modelos más utilizados en la actualidad, el rotor Darrieus (1921) y el rotor Savonius (1924), este último fue inventado por el ingeniero finlandés Sigurd J Savonius y tiene un diseño básico con dos medios cilindros que giran alrededor de un eje. En esta investigación se analizan cuatro modelos diferentes de hélices para el rotor Savonius, al igual que el rotor tradicional. El objetivo principal es encontrar el mejor coeficiente de potencia (Cp.), al igual que el coeficiente de torque $(\mathrm{Cm})$ en los diferentes modelos. Para lograr este objetivo se utiliza modelado computacional CFD, con simulaciones $3 D$ en régimen transitorio. El dominio computacional se define como una función de la longitud mínima en el sistema, y el mallado se realiza después de un análisis de independencia del tamaño de malla. En los resultados se aprecia que el rotor Savonius helicoidal presenta el mejor desempeño en las condiciones de operación analizadas, mejorando en cerca de $20 \%$ sobre las otras configuraciones. Además, el rotor de 3 hélices presenta el rendimiento más bajo con un coeficiente de poder Cp. de 0,073.

Palabras clave: Savonius, energía eólica, turbina vertical, estudio numérico, CFD.

\section{INTRODUCTION}

The increase in per capita energy use and high energy demand by the modern industrial processes have incremented drastically energy consumption
[1], and since the energy sources are mostly fossil fuels the resultant pollution levels are affecting the planet's ecosystems. Due to this fact, a growing interest in finding new efficient and clean ways to produce energy has appeared recently. Alternative

1 Programa de ingeniería mecánica. Universidad Autónoma del Caribe. 080020. Barranquilla, Colombia.

E-mail: apalencia@uac.edu.co; ing.giovannij@yahoo.com; khriscia.utria@uac.edu.co 
energies have become important since they show promising capacity to supply today's energy demand thus minimizing the environmental impact. One of the most used is the wind energy; many studies have been developed with the purpose to improve its process efficiency [1-24]

Currently, there are two types of wind turbines, the horizontal axis turbines and the vertical axis turbines, which have as principal characteristic the axis position. The advantages of vertical turbines are several e.g. the capacity to operate in a wide range of wind conditions, simple construction and lack of control mechanisms in the wind direction. However, today vertical turbines have low efficiencies [2], thus several researches have as principal goal to evaluate and improve their performances. Also, several studies have been developed in the past few years to evaluate Savonius behavior under different operation conditions [1-3]. They even include modifications in the basics configuration to improve the performance.

Later studies[4-7] were developed using wind tunnels to simulate different operation conditions and to obtain the efficiency profile of Savonious turbine with different configurations. Afterward, the studies focused in finding new propeller profiles, which improved the efficiency [8-13], using the power generated by the turbine. Obstacles were also proposed to decrease the negative torque produced during the operation.

Several studies compared different computational and experimental rotor geometries [14-17], evaluating the performance from power coefficient $(\mathrm{Cp}$ ) standpoint and torque coefficient's $(\mathrm{Cm})$; recent studies [18][20] compare conventional and modified Savonius wind turbine and evaluate the flow patron structure.

On the other hand, researches have compared through energetic and exegetic analysis the performance of vertical and horizontal turbines [21], the evolution of the researches was described in [22-23].

This research proposes finding the best power coefficient $(\mathrm{Cp})$ and torque coefficient $(\mathrm{Cm})$ for each of the different models that are studied. To achieve the goal a computational model CFD, with 3D simulations in transient regimen is used.

\section{PROCEDURE}

The following describes in detail each of the steps in the turbine simulation process.

\section{Rotor Savonius}

Savonius Rotor (Figure 1) is a vertical axis turbine, which presents the lowest efficiency of the wind turbines about $10 \%$ (0.6 T.S.R, basic model). However, it posses certain advantages that make it more interesting to use in small generation projects: its components are over ground, which means it does not need frames; its running does not depend on the wind direction; it operates at low wind velocities and its construction is cheaper and less complex than others'.

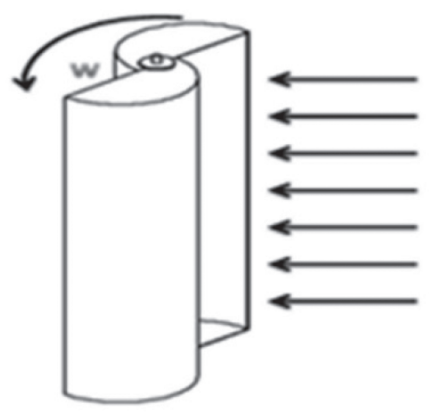

Figure 1. Savonius Rotor.

\section{Rotor Models}

This research has studied four different rotors (Figure 2): a classic modified rotor, which is expected to have a better efficiency than the traditional one; double step, helical and triple blade models. It is expected that models decrease their efficiency and have better stability on the pulsating rotor momentum. All the selected models have a superior and inferior diameter $10 \%$ higher than the rotor diameter in order to improve the performance, and also a slenderness ratio of 2.5. Finally none of the models presents overlapping, due to its low significance in the equipment performance [24].

The swept area in all the models was the same, despite the different geometries; the area of the vertical axis rotor was defined by the swept area, which is:

$$
A=H^{*} D
$$




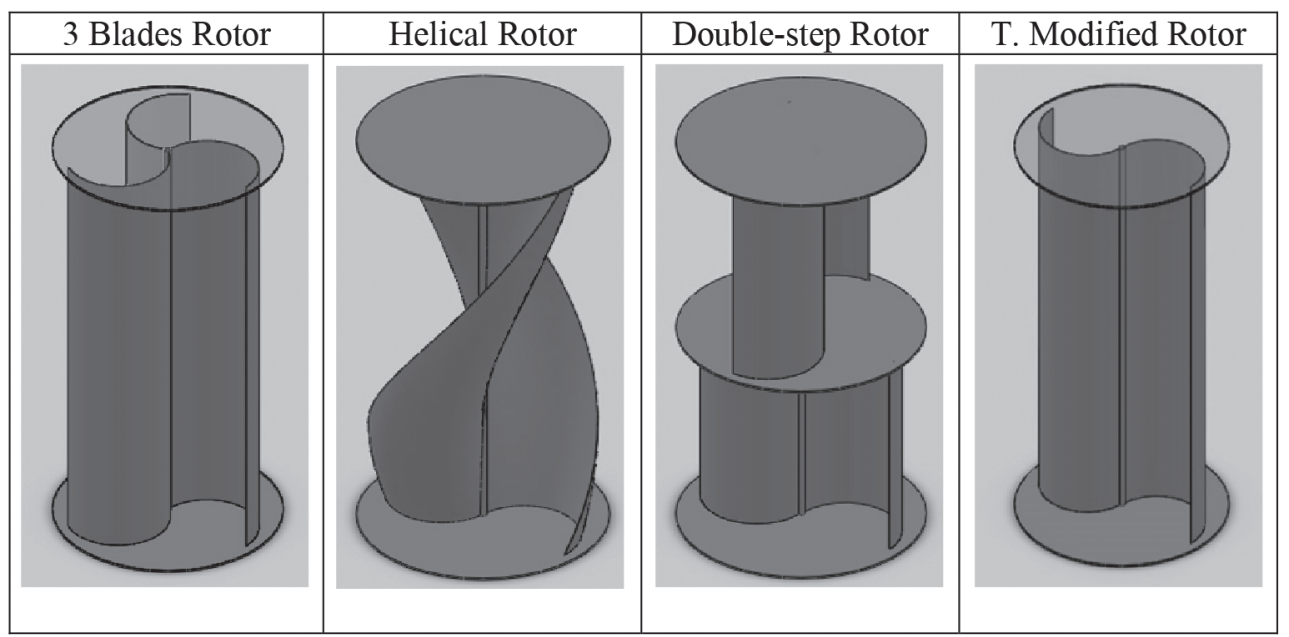

Figure 2. Rotor Models.

The tested rotor dimensions are as follow: Height $0.20 \mathrm{~m}$ and diameter $0.09 \mathrm{~m}$. These dimensions are maintained in all the models changing only the geometry.

\section{Computational Model}

The computational domain was defined as a function of the minimal size that does not affect the results obtained during the simulations; it is necessary that the wind wake generated by the passing over the turbine is fully developed. The computational domain was finally selected as a result of preview simulations, which show the total covering of the wakes produced by the rotor. The final dimensions of the computational domain are shown in Table 1.

Table 1. Computational Domain

\begin{tabular}{|c|c|c|c|}
\hline Axis & $\begin{array}{c}\text { Initial } \\
\text { Point }(\mathbf{m})\end{array}$ & $\begin{array}{c}\text { Rotor Point } \\
(\mathbf{m})\end{array}$ & $\begin{array}{c}\text { Final Point } \\
(\mathbf{m})\end{array}$ \\
\hline $\mathrm{X}$ & 1 & 0 & -7 \\
\hline $\mathrm{Y}$ & 0.5 & 0 & -0.5 \\
\hline $\mathrm{X}$ & 0.4 & 0 & -0.4 \\
\hline
\end{tabular}

Mass and momentum equations used in the computational model (Liquid flows are supposed to be incompressible):

\section{Continuity}

$$
\frac{\partial u}{\partial x}+\frac{\partial v}{\partial y}+\frac{d w}{d z}=0
$$

Momentum along $\mathrm{x}$-axis:

$$
\begin{aligned}
u \frac{\partial u}{\partial x}+v & \frac{\partial u}{\partial y}+w \frac{\partial u}{\partial z} \\
& =-\frac{1}{\rho} \frac{P^{\prime}}{\partial x}+v\left(\frac{\partial^{2} u}{\partial x^{2}}+\frac{\partial^{2} u}{\partial y^{2}}+\frac{\partial^{2} u}{\partial z^{2}}\right)
\end{aligned}
$$

Momentum along y-axis:

$$
\begin{aligned}
\mathbf{u} \frac{\partial \mathbf{v}}{\partial \mathbf{x}}+\mathbf{v} \frac{\partial \mathbf{v}}{\partial \mathbf{y}}+\mathbf{w} \frac{\partial \mathbf{v}}{\partial \mathbf{z}} & \\
& =-\frac{1}{\rho} \frac{\mathbf{P}}{\partial \mathbf{y}}+\mathbf{v}\left(\frac{\partial^{2} \mathbf{v}}{\partial \mathbf{x}^{2}}+\frac{\partial^{2} \mathbf{v}}{\partial \mathbf{y}^{2}}+\frac{\partial^{2} \mathbf{v}}{\partial \mathbf{z}^{2}}\right)
\end{aligned}
$$

Momentum along z-axis:

$$
\begin{aligned}
u \frac{\partial w}{\partial x}+v & \frac{\partial w}{\partial y}+w \frac{\partial w}{\partial z} \\
& =-\frac{1}{\rho} \frac{P^{\prime}}{\partial z}+v\left(\frac{\partial^{2} w}{\partial x^{2}}+\frac{\partial^{2} w}{\partial y^{2}}+\frac{\partial^{2} w}{\partial z^{2}}\right)
\end{aligned}
$$

The equations for the K-epsilon Turbulence Model are as followed: 
Transport equation for the kinetic energy K:

$$
\begin{aligned}
\frac{\partial}{\partial \mathbf{t}}(\rho \mathbf{k})+ & \frac{\partial}{\partial \mathbf{x}_{\mathbf{i}}}\left(\rho \mathbf{k} \mathbf{u}_{\mathbf{i}}\right) \\
= & \frac{\partial}{\partial \mathbf{x}_{\mathbf{j}}}\left[\left(\mu+\frac{\mu_{\mathbf{t}}}{\sigma_{\mathbf{k}}}\right) \frac{\partial \mathbf{k}}{\partial \mathbf{x}_{\mathbf{j}}}\right]+\mathbf{P}_{\mathbf{k}} \\
& +\mathbf{P}_{\mathbf{b}}-\rho-\mathbf{Y}_{\mathbf{M}}+\mathbf{S}_{\mathbf{k}}
\end{aligned}
$$

For the dissipation $\epsilon$

$$
\begin{aligned}
\frac{\partial}{\partial \mathbf{t}}(\rho \in) & +\frac{\partial}{\partial \mathbf{x}_{\mathbf{i}}}\left(\rho \in \mathbf{u}_{\mathbf{i}}\right) \\
= & {\left[\left(\mu+\frac{\mu_{\mathbf{t}}}{\sigma_{\epsilon}}\right) \frac{\partial \epsilon}{\partial \mathbf{x}_{\mathbf{j}}}\right] } \\
& +\mathbf{C}_{1 \in} \frac{\epsilon}{\mathbf{k}}\left(\mathbf{P}_{\mathbf{k}}+\mathbf{C}_{3 \in} \mathbf{P}_{\mathbf{b}}\right)-\mathbf{C}_{2 \epsilon} \rho \frac{\epsilon^{2}}{\mathbf{k}}+\mathbf{S}_{\epsilon}
\end{aligned}
$$

Turbulence Viscosity:

$$
\mu_{\mathrm{t}}=\rho \mathrm{C}_{\mu} \frac{\mathrm{k}^{2}}{\epsilon}
$$

Kinetic energy production k:

$$
\mathbf{P}_{\mathbf{k}}=-\rho \overline{\mathbf{u}_{\mathbf{i}}} \overline{\mathbf{u}_{\mathbf{j}}} \frac{\partial \mathbf{u}_{\mathbf{j}}}{\partial \mathbf{x}_{\mathbf{i}}}
$$

Buoyancy effect

$$
\mathbf{P}_{\mathbf{b}}=\beta \mathbf{g}_{\mathbf{i}} \frac{\mu_{\mathbf{t}}}{\operatorname{Pr}} \frac{\partial \mathbf{T}}{\partial \mathbf{x}_{\mathbf{i}}}
$$

Model constants:

$$
\mathrm{C}_{1 \in}=1,44, \mathrm{C}_{2 \epsilon}=1,92, \mathrm{C}_{\mu}=0,09, \sigma_{\mathrm{k}}=1, \sigma_{\epsilon}=1,3
$$

\section{Meshing}

The meshing process is important due to its direct influence on the simulation results. In the first stage, is developed the dependency analysis of meshing size.

\section{Mesh Dependence}

Figure 3 shows results for mesh analysis for different models. The stability is over $\sim 500,000$ nodes for the torque in each model. These nodes number allows the real time to get increased, where the turbine performance is simulated; as results better comprehension of its behavior and the tendencies of the forces (which affect its performance) are obtained. Table 2 shows the final values of the nodes and element number.

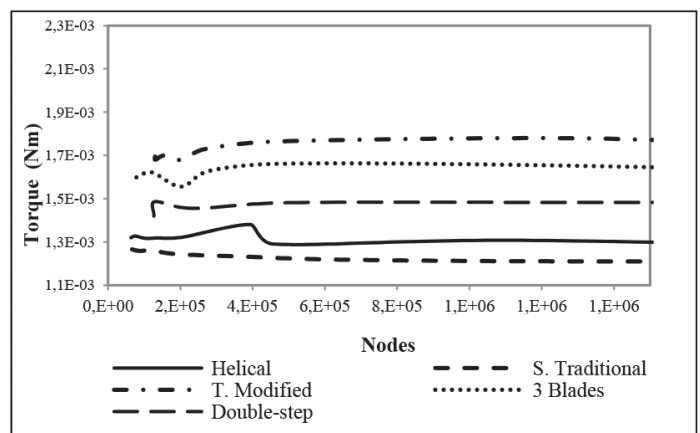

Figure 3. Results of the mesh dependence for different models

Table 2. Number of nodes and simulation elements.

\begin{tabular}{|l|c|c|}
\hline \multicolumn{1}{|c|}{ Turbine } & $\begin{array}{c}\text { Node } \\
\text { number }\end{array}$ & $\begin{array}{c}\text { Element } \\
\text { number }\end{array}$ \\
\hline Traditional Savonius & 456,019 & 2580655 \\
\hline Double Step S. & 493,156 & 2753655 \\
\hline Helicoidal Savonius & 457,359 & 2548903 \\
\hline Triple blade S & 472,515 & 2612818 \\
\hline S.T. Improved & 464,797 & 2587275 \\
\hline
\end{tabular}

\section{Boundary Conditions}

Boundary conditions do not change in the simulations in order to have comparable results. Modified values are related to characteristics and geometries of each rotor model, such as mass and inertia momentum. The simulation time is 12 seconds with a time step of 0.01 seconds.

Navier-Stokes and continuity equations are used to perform fluid analysis. The $k-\varepsilon$ standard based on pressure models of turbulence are used, to solve the torque equations with standard treatment for the walls.

\section{RESULTS AND DISCUSSION}

All the simulations are developed in a computer with an Intel ${ }^{\circledR}$ core $^{\mathrm{TM}}$ processor i7-2630QM. PC Frequency of $2.00 \mathrm{GHz}$ and RAM memory of $8 \mathrm{~Gb}$. 
Simulations are made in parallel with duration $\sim 80$ hours each one.

Figure 4 corresponds to the last instant of time in the simulation of triple, modified helical and traditional Savonius rotor blade. Velocity contours are shown in a perpendicular plane to the rotor. They vary with the rotor height for the models within continuous geometry in their propellers such as double-pass model (3D model); it is noticed that the wake behind the rotor wind tends to lean toward the rotation direction for different models.

Torque coefficient $(\mathrm{Cm})$ analysis is important to compare the efficiency between the models, hence use properly the wind kinetic energy to select the best model for a specific application. Figure 5 shows momentum coefficient for all the configurations.

It can be noticed that Savonius traditional and modified traditional rotors, present peak-to-peak amplitude higher than in others models, having an important impact in the total efficiency. They also have the highest values of $\mathrm{Cm}$, however their torque coefficient peaks are the lowest thus decreasing the efficiency for these two models.

Although, 3-blade rotor does not have negative torque coefficient peaks (min 0.05) its maximum values are the lowest (max 0.20), which makes it the least efficient comparing with others, even with traditional Savonius.

Despite the fact that helical rotors or 2-step rotors do not have the highest values of $\mathrm{Cm}$, the peak to peak amplitudes are the lowest $(0.35-0.25$ for helical and $0.19-0.25$ for 2 -step), hence a higher efficiency is obtained, if it is compared to the others models.

On the other hand, the results obtained for the $\mathrm{Cp}$ are shown in Figure 6; the highest values of the efficiency are found in a T.S.R. of 0.6 in each model.

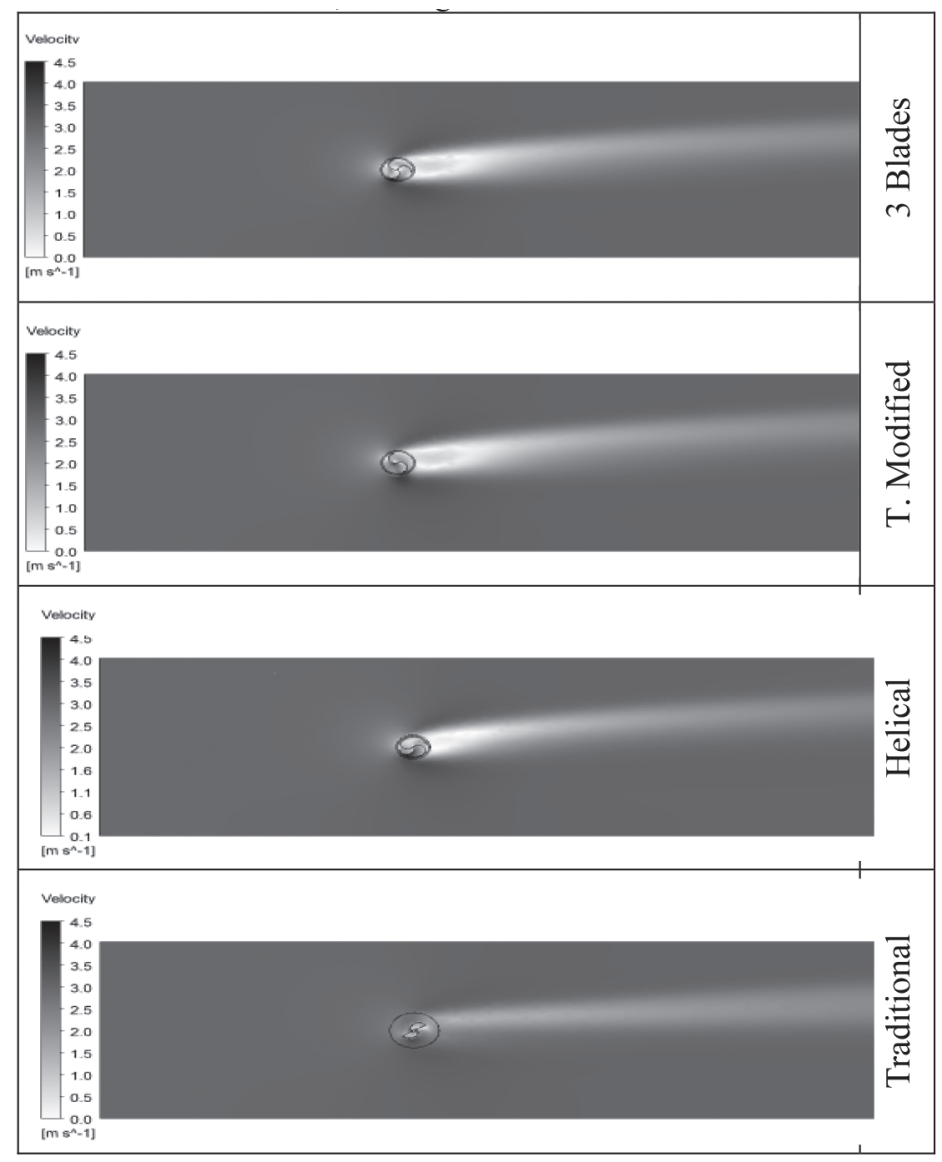

Figure 4. Savonius rotor velocity Contourns. 


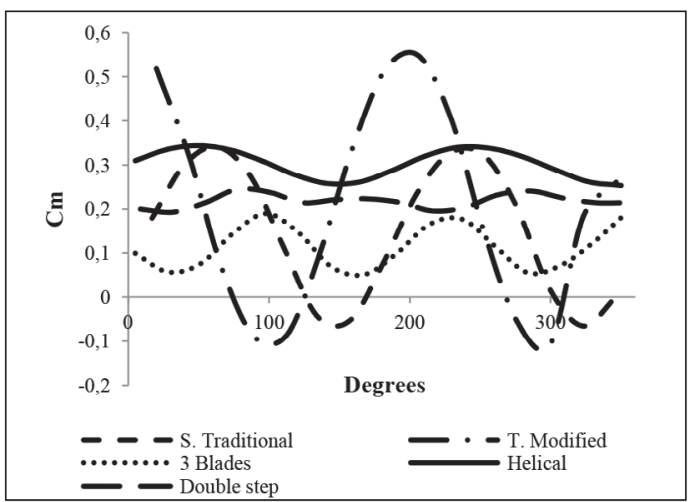

Figure 5. $\mathrm{Cm}$ for different models during turbine rotation

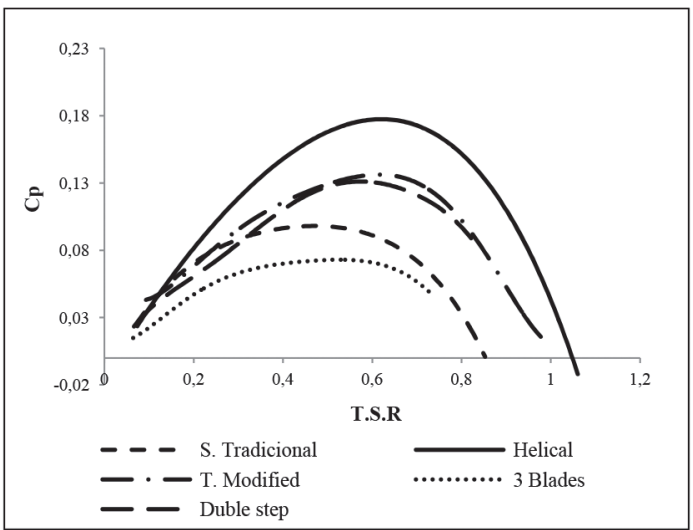

Figure 6. Power Coefficient Vs. T.S.R.

Traditional Savonius rotor presents an efficiency close to $10 \%$, which agrees with previous consulted publications [13, 18-20], showing the reliability of performed process.

3-blade rotor is the model with the lowest efficiency $\sim 7 \%$, (even lower than the traditional rotor). The modified model reaches values of $15 \%$ for the $\mathrm{Cp}$, remaining the unstable trend of the other models. 2 -step rotor presents a $\mathrm{Cp} \sim 13 \%$, with a stable behavior. Helical rotor is the one with the best efficiency $(\sim 18 \%)$, almost twice the efficiency of the traditional rotor and maintaining a constant higher behavior above the other tested models.

When the perimeter velocity increases, the $\mathrm{Cp}$ values decrease for all the models tested, they even achieve negative values for T.S.R higher than one.

\section{CONCLUSIONS}

A computational model was used to analyze four different Savonius rotor configurations through 3D simulations in transient regimen to find the best power coefficient $(\mathrm{Cp})$ and the torque coefficient $(\mathrm{Cm})$.

This research found that 3-blade rotor presents the lowest performance of all the models with a power coefficient $\mathrm{Cp}$, of 0.073 ; moreover it has a poor efficiency due to its low values of torque coefficient.

2-step and modified traditional rotors present greater performance than the traditional rotor, with coefficient power values around 0.15 and 0.13 . These values are higher than the traditional rotor, but they do not overcome the helical rotor.

Savonius rotor model with a helical coil has the best behavior both for the power coefficient and torque coefficient. For the $\mathrm{Cp}$. values of $18 \%$ are achieved. Regarding its $\mathrm{Cm}$ values, although they do not have the highest peaks, they are more stable between 0.25 and 0.35 , showing the cause of their high efficiency.

\section{REFERENCES}

[1] U.K. Saha and M.J. Rajkumar. "On the performance analysis of Savonius rotor with twisted blades". Renew. Energy. Vol. 31 No 11, pp. 1776-1788. September, 2006.

[2] K. Irabu and J.N. Roy. "Characteristics of wind power on Savonius rotor using a guidebox tunnel". Exp. Therm. Fluid Sci. Vol. 32 $\mathrm{N}^{\mathrm{o}}$ 2, pp. 580-586. November, 2007.

[3] B.D. Altan and M. Atılgan. "An experimental and numerical study on the improvement of the performance of Savonius wind rotor". Energy Convers. Manag. Vol. $49 \mathrm{~N}^{\mathrm{o}} 12$, pp. 3425-3432. December, 2008.

[4] U.K. Saha, S. Thotla and D. Maity. "Optimum design configuration of Savonius rotor through wind tunnel experiments". J. Wind Eng. Ind. Aerodyn. Vol. 96 No 8-9, pp. 13591375. August, 2008.

[5] M.M. and J. Da. "Velocity Measurement of Flow Around Model Vertical Axis Wind Turbines". Int. J. Green Energy. Vol. 5 No 1-2, pp. 55-68. February, 2008. 
[6] M.a. Kamoji, S.B. Kedare and S.V. Prabhu. "Experimental investigations on single stage modified Savonius rotor". Appl. Energy.

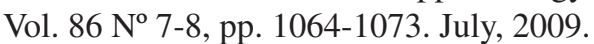

[7] P. Ghosh, M.a. Kamoji, S.B. Kedare and S.V. Prabhu. "Model Testing of Single- and Three-Stage Modified Savonius Rotors and Viability Study of Modified Savonius Pump Rotor Systems". Int. J. Green Energy. Vol. 6 No 1, pp. 22-41. March, 2009.

[8] M.a. Kamoji, S.B. Kedare and S.V. Prabhu. "Performance tests on helical Savonius rotors". Renew. Energy. Vol. 34 No 3, pp. 521529. March, 2009.

[9] M.H. Mohamed, G. Janiga, E. Pap and D. Thévenin. "Optimization of Savonius turbines using an obstacle shielding the returning blade". Renew. Energy. Vol. 35 $\mathrm{N}^{\circ}$ 11, pp. 2618-2626. November, 2010.

[10] B.D. Altan and M. Attlgan. "The use of a curtain design to increase the performance level of a Savonius wind rotors". Renew. Energy. Vol. 35 No $^{\circ}$, pp. 821-829. April, 2010.

[11] M.H. Mohamed, G. Janiga, E. Pap and D. Thévenin. "Optimal blade shape of a modified Savonius turbine using an obstacle shielding the returning blade". Energy Convers. Manag. Vol. $52 \mathrm{~N}^{\circ}$ 1, pp. 236-242. January, 2011.

[12] K. Irabu and J.N. Roy. "Study of direct force measurement and characteristics on blades of Savonius rotor at static state". Exp. Therm. Fluid Sci. Vol. 35 No 4, pp. 653-659. May, 2011.

[13] H. Ersoy and S. Yalçındağ. "An experimental study on the improvement of Savonius turbine performance using flexible sails". Int. J. Green Energy. Vol. 11, pp. 796-807. 2014.

[14] N.H. Mahmoud, a.a. El-Haroun. E. Wahba and M.H. Nasef. "An experimental study on improvement of Savonius rotor performance". Alexandria Eng. J. Vol. 51 № 1, pp. 19-25. March, 2012.

[15] S. McTavish, D. Feszty and T. Sankar, "Steady and rotating computational fluid dynamics simulations of a novel vertical axis wind turbine for small-scale power generation". Renew. Energy. Vol. 41, pp. 171-179. May, 2012.

[16] P. Jaohindy, S. McTavish, F. Garde and A. Bastide. "An analysis of the transient forces acting on Savonius rotors with different aspect ratios". Renew. Energy. Vol. 55, pp. 286-295. July, 2013.

[17] A. Damak, Z. Driss and M.S. Abid. "Experimental investigation of helical Savonius rotor with a twist of $180^{\circ}$ ". Renew. Energy. Vol. 52, pp. 136-142. April, 2013.

[18] K. Kacprzak, G. Liskiewicz and K. Sobczak. "Numerical investigation of conventional and modified Savonius wind turbines". Renew. Energy. Vol. 60, pp. 578-585. 2013.

[19] T. Zhou and D. Rempfer. "Numerical study of detailed fl ow fi eld and performance of Savonius wind turbines". Renew. Energy. Vol. 51, pp. 373-381. 2013.

[20] K. Morshed, M. Rahman, G. Molina and M. Ahmed. "Wind tunnel testing and numerical simulation on aerodynamic performance of a three-bladed Savonius wind turbine". Int. J. Energy Environ. Eng. Vol. $4 \mathrm{~N}^{\circ}$ 1, p. 18. 2013.

[21] K. Pope, I. Dincer and G.F. Naterer. "Energy and exergy efficiency comparison of horizontal and vertical axis wind turbines". Renew. Energy. Vol. 35 N 9, pp. 2102-2113. September, 2010.

[22] J.V. Akwa, H.A. Vielmo and A.P. Petry. "A review on the performance of Savonius wind turbines". Renew. Sustain. Energy Rev. Vol. 16 No 5, pp. 3054-3064. Juny, 2012.

[23] S. Roy and U.K. Saha, "Review on the numerical investigations into the design and development of Savonius wind rotors," Renew. Sustain. Energy Rev. Vol. 24, pp. 73-83. Aug. 2013.

[24] J. Sargolzaei and a. Kianifar. "Modeling and simulation of wind turbine Savonius rotors using artificial neural networks for estimation of the power ratio and torque". Simul. Model. Pract. Theory. Vol. $17 \mathrm{~N}^{\circ} 7$, pp. 1290-1298. August, 2009. 